\title{
Festa popular e identidade nacional nos dois lados do Atlântico durante o século $\mathrm{XX}^{*}$
}

\author{
Popular feast and national identity in both margins \\ of the Atlantic during the tweentieth century \\ Fiesta popular e identidad nacional a ambas orillas \\ del Atlántico durante el siglo XX
}

Daniel Melo**

\begin{abstract}
Resumo: Neste texto reflete-se sobre as relações entre festa popular e identidade nacional no Brasil e em Portugal durante o século XX, partindo da análise comparativa de duas manifestações culturais centrais nos dois países: o desfile das escolas de samba do Rio de Janeiro e as marchas populares de Lisboa. O exercício, sustentado num conjunto relevante de estudos sobre cada um dos casos, justificou-se pela riqueza de similitudes no processo histórico, no conteúdo, na estrutura e na organização destes desfiles populares urbanos. Nele se realçou ainda a importância dos períodos ditatoriais para a construção e centralidade dessas festas urbanas.
\end{abstract}

Palavras-chave: identidade cultural; nacionalismo; politica cultural.

Abstract: This text reflects on the relationship between national identity and popular feast in Brazil and Portugal during the $20^{\text {th }}$ century, from a comparative analysis of two nuclear cultural events: the samba schools' parade in Rio de Janeiro and the popular marches of Lisbon. The exercise, held in a relevant set of studies on each of the cases, is justified by the substantive set of similarities both in the historical process, the content, the structure, and the organization of those urban popular parades. In it we noted the importance of the dictatorial periods for construction and urban centrality of these parties.

Keywords: cultural identiy; nationalism; cultural policy.

\footnotetext{
* Este trabalho é um resultado de financiamento concedido pela Fundação para a Ciência e a Tecnologia (FCT), sob a forma de bolsa de pós-doutoramento.

**Investigador integrado do CHAM (Centro de História d'Aquém e d'Além-Mar/Portuguese Centre for Global History), Faculdade de Ciências Sociais e Humanas, Universidade Nova de Lisboa e Universidade dos Açores. <daniel.melo@ffcsh.unl.pt>.
} 
Resumen: Este texto reflexiona sobre la relación entre la identidad nacional y la fiesta popular en Brasil y Portugal durante el siglo XX, a partir del análisis comparativo de dos eventos culturales nucleares en ambos países: el desfile de las escuelas de samba en Río de Janeiro y las marchas populares en Lisboa. El trabajo, apoyado en un conjunto relevante de estudios sobre cada uno de los casos, se justifica por las similitudes substantivas en el proceso histórico, el contenido, la estructura y la organización de los desfiles populares urbanos. En él se puede comprobar la importancia de los periodos dictatoriales para la construcción y la centralidad de estas fiestas urbanas.

Palabras clave: identidad cultural; nacionalismo; política cultural.

Este texto propõe uma reflexão sobre as relações entre festa popular e identidade nacional no século XX, comparando a evolução registada no Brasil e em Portugal. Tendo essa centúria sido marcada contraditoriamente pelas forças do cosmopolitismo e do nacionalismo, os casos brasileiro e português são assaz relevantes, pois, a vigência, nestes países, de ditaduras com lastro e de forte pendor nacionalista possibilita estudar de modo mais aprofundado similitudes e diferenças de políticas culturais e relacionamentos socioculturais e ideológicos entre Estado e sociedade civil organizada sob distintos regimes políticos. Esta é uma problemática que tem tido um acolhimento especial na literatura académica das últimas décadas. Contudo, o grosso dos estudos centra-se em cruzamentos ou tentames comparativos entre os regimes europeus de "terceira via" mais proeminentes no período de entre guerras (nazismo, fascismo, franquismo) ou entre algumas das ditaduras latino-americanas do período da Guerra Fria ${ }^{1}$. Estão em crescendo os estudos comparando os regimes ditatoriais brasileiros e português no campo político, cultural, etc., daí também a pertinência desta proposta² .

Dada a ausência de consenso académico quanto a uma definição única de nacionalismo, procura-se aqui perspectivá-lo a partir dos debates atuais. Nesse sentido, afigura-se operativa a proposta de Anthony D. Smith, para o qual o nacionalismo é o "movimento ideológico que procura alcançar e manter a autonomia, unidade e identidade para uma

A título de exemplo e para os regimes de "terceira via", ver: Milza, 1991; Mann, 2004; Paxton, 2005; Pinto, 2010. Para a América Latin, ver: Bethell, 2005; Palacios, 2008; Beired; Capelato; Prado, 2010. Na confluência dos dois tipos de regimes, conferir: Pasetti, 2006; Torgal e Paulo, 2008; Hauser, 2011.

2 No campo cultural cabe destacar: Paulo, 1994; Lopes, 1998; Fiuza, 2005 e 2006; Guimarães, 2009; Costa, 2010; Sarmento e Guimarães, 2010. Cobrindo um arco temporal e espacial maior, Carneiro, 2001. Para o presente tentame comparativo inspiro-me em Bloch, 2006. 
população que alguns dos seus membros pensam constituir uma 'nação', atual ou potencial" (1991, p. 73 e 71-72 apud SOBRAL, 2003, p. 1103). Nação essa que é um conjunto histórico dotado de carácter étnico e simbólico-cultural, consubstanciada numa "dada população humana que habita um território histórico e que partilha mitos e memórias históricas comuns, uma cultura pública e de massas, uma economia comum e os mesmos direitos e deveres legais para todos os seus membros" (SMITH, 1991, p. 43 apud SOBRAL, 2003, p. 1101).

Daqui decorre uma identidade nacional dinâmica, em permanente reconstrução como "resposta a determinadas necessidades, interesses e percepções, embora sempre dentro de determinados limites", tornando relevantes os processos de recorrência, continuidade e reapropriação no nexo entre passado e presente (SMITH, 1999, p. 17 apud SOBRAL, 2003, p. 1103). Processos esses que, adita Sobral, são "diversos consoante as classes e grupos sociais" (2003, p. 1121).

Esta perspectiva permite perceber melhor o lugar das festas, em particular das que são o objeto do presente artigo, e a sua relevância em termos de construção da nação e duma identidade nacional. Ora, se essa identidade nacional se vai transformando ao longo do tempo, mais interesse tem analisar o contributo das festas nacionais, bem como a sua evolução interna, nas principais dimensões estruturantes. A relevância desse estudo torna-se assim independente de saber em que época emergiu uma identidade nacional para cada um dos países em apreço, pois se se pode concordar que "a generalização da consciência da identidade nacional pela totalidade da população portuguesa" se torna um fato em 1890-1926 (MATTOSO, 1998, p. 21 apud SOBRAL, 2003, p. 1110), tal não obvia a que se deva estudar a evolução dessa mesma identidade, para surpreender continuidades e transformações relevantes. O que é extensivo ao Brasil. Como aduz Sobral (2003, p. 1121): “Conjunturas específicas [...] devem ser articuladas com a manutenção de estruturas de longa duração para compreender como é que a identificação com uma nação - um produto da história - se torna algo da ordem do natural".

Ademais, entre os principais fatores para essa tomada de consciência contam-se "a intervenção do próprio Estado, envolvido na criação de uma cultura nacionalista assente na escola, na instituição de rituais coletivos, na generalização das relações com a política através de uma maior participação nos seus processos, tudo associado à ação de uma imprensa de massas" (SOBRAL, 2003, p. 1110). É no âmbito dos rituais coletivos, e do seu fomento pelo Estado, que se pode inscrever o papel das festas populares. 
De modo a poder contribuir para esse aprofundamento no espaço curto dum artigo, propõe-se um olhar cruzado sobre duas festas populares centrais no século XX de cada país: o desfile das escolas de samba do Rio de Janeiro e as marchas populares de Lisboa. Embora com diferenças relevantes (por exemplo, de quadra festiva), tais festejos têm um conjunto de afinidades e homologias no respeitante ao processo histórico (festa nacional e nacionalista) e à sua essência (conteúdo, estrutura e organização). Isso mesmo procurarei demonstrar seguidamente. Nesse sentido, o presente texto permite prolongar a análise dos processos de criação de cultura popular urbana e de intercâmbio cultural entre estes dois países ao nível das danças e cantos populares na contemporaneidade. ${ }^{3}$

\section{Processo histórico: símbolos de cultura nacional e nacionalista}

O desfile de samba carioca e as marchas populares lisboetas representaram a dada altura do seu percurso no século XX (e representam ainda na atualidade) as festas nacionais por excelência dos respectivos países. Não quer dizer que sejam festas cívicas patrióticas, ao jeito do Dia da Independência nos EUA, mas sim festividades culturais mais simbólicas. Tal não significa também que sejam exclusivistas (há outros símbolos e festividades relevantes), mas sim que atingiram uma dimensão mais central, mais abrangente, porque a isso almejaram. Com efeito, estes eventos foram oficialmente viabilizados e tornados centrais como contrapartida para o fato de terem assumido o repto de festa nacional, $a$ festa nacional. Isto sucedeu durante um período histórico de grande fervor nacionalista, que muito influenciou a sua evolução.

Os processos históricos em apreço tiveram o seu início após a I Guerra Mundial, no contexto dum movimento de recuperação da cultura folclórica/folclorização (sobretudo no caso luso) e da preocupação de correntes sociais/culturais com a construção duma identidade nacional integradora, ambos fenómenos culturais da modernidade ocidental ${ }^{4}$.

No Rio, as escolas de samba resultaram da inspiração, mistura e transformação de ranchos, blocos, cordões de rua e do samba-de-roda baiano que se exibiam na quadra carnavalesca. Embora parte destas

\footnotetext{
3 Ver: Tinhorão, 1994, p. 9-10.

4 Para o caso brasileiro, ver: Vianna, 1995 e Augras, 1998; para o caso português: Melo, 2001. Para a compreensão do quadro internacional da consolidação do processo de folclorização ver: Cavazza, 1997 e Castelo-Branco; Branco, 2003, p. 1-21.
} 
manifestações populares culturais já viesse de finais do século XIX (um dos ranchos pioneiros, Reis de Ouro, foi fundado em 1893, o samba-de-roda baiano foi levado por baianos radicados no Rio nos fins de oitocentos), só se consolidaram e consagraram no século seguinte (AUGRAS, 1998, p. 17). O mesmo sucedeu com as marchas populares de Lisboa, que recuperaram antigos folguedos populares dos santos de junho e os mesclaram com influências das cegadas carnavalescas, dos arraiais, da animação dos mercados públicos, das marches aux flambeau e do teatro de revista (MELO, 2001, p. 279).

\section{A invenção da tradição}

O primeiro desfile de samba deu-se num concurso informal organizado por Zé Espinguela, em 20/1/1929, onde competiram o Conjunto Oswaldo Cruz (futura Portela), a Mangueira e o Estácio. Cada qual exibiu dois sambas, mas a polémica da classificação comprometeu a sua continuidade imediata. Só retomaria em 7/2/1932, por iniciativa do jornal Mundo Sportivo, também na Praça Onze. Participaram então 19 escolas, mas só 5 destas foram premiadas, por um inédito júri formado por jornalistas e intelectuais. Em 1933 surge o primeiro samba-enredo (pela Unidos da Tijuca), isto é, uma canção específica com letra ligada ao tema (enredo) do desfile (da cenografia-coreografia) da escola. Doravante, o desfile do samba será enquadrado pela Prefeitura do Rio (com apoio financeiro da Secção de Turismo do DIP- Departamento de Informação e Propaganda), obedecendo a um regulamento rígido e minucioso. No ano seguinte, as escolas foram subsidiadas pelo desfile pago no dia do padroeiro S. Sebastião, embora recebessem uma porção diminuta face às grandes sociedades, aos ranchos e aos blocos carnavalescos então participantes. Em poucos anos, portanto, o desfile de samba tinha não só elaborado a sua estrutura básica como sido reconhecido e integrado pelas autoridades (AUGRAS, 1998, p. 25-38).

A primeira exibição das marchas populares lisboetas deu-se num concurso organizado pelo animador cultural e cineasta Leitão de Barros, em 1932, numa encomenda estival para o popular recinto de espetáculos Parque Mayer, apoiada por jornais e empresas ${ }^{5}$. Participaram 3 marchas bairristas (dos bairros Campo de Ourique, Bairro Alto e Alto do Pina), então ainda designadas por ranchos, pois era o termo mais em voga

5 Leitão de Barros era então um dinamizador cultural ligado aos modernistas, director de suplementos culturais como O Noticias Ilustrado, o que lhe permitia estar a par do que ocorria no mundo, Brasil incluído. 
para designar os agrupamentos festivos (tal como ocorrera no Brasil). $\mathrm{O}$ nome de marchas derivou muito provavelmente do concurso se ter chamado "Marcha dos ranchos" e de futuramente estas desfilarem ao som de um tambor (ou caixa). Cada marcha foi organizada por uma associação cultural-recreativa bairrista ${ }^{6}$. O êxito foi tal que se organizou uma 2. ${ }^{\text {a }}$ edição nesse mesmo mês, com o dobro dos grupos participantes. Logo a partir de 1934, o concurso, já em desfile e regulamentado, estará a cargo do município de Lisboa (o equivalente à prefeitura no Brasil). Assim, também em poucos anos, o desfile das marchas foi estruturado, reconhecido e integrado pelas autoridades (MELO, 2001, p. 278-288).

Outro aspecto relevante é que também em ambos os casos a sua essência foi definida como sendo algo de enraizado localmente e, portanto, folclórico. No caso brasileiro, a genuinidade carioca é sobretudo realçada no período getulista: segundo a imprensa coeva, "as escolas de samba se apresentarão com enredos e com músicas característicos, com letras e ritmos nascidos lá no morro"7. No caso luso, ainda antes da estreia, o evento foi promovido como tradição festiva local, antevendo-se "a revivescência das velhas marchas populares que, de cada bairro da cidade, nas noites festivas dos Santos Populares se encontravam no chafariz da antiga Rua Formosa [atual Rua do Século, no Bairro Alto]". ${ }^{8}$ A imprensa arregimentada fez eco deste 'reencontro' com as raízes, ou melhor, da 'recriação' da tradição, em textos onde se assinalava o carácter genuíno e popular do evento. Os jornais ampliaram também a opinião do júri do concurso, que constituía um verdadeiro programa de intenções: "lançaram-se os fundamentos para uma grande festa anual, tipicamente portuguesa e popular, a organizar com extensão e superior critério, e que a Câmara Municipal devia tomar a si". ${ }^{9}$

Pode assim considerar-se que estas festividades representativas da cultura nacional são o resultado de complexos, mas rápidos, processos de invenção de tradições (na formulação de HOBSBAWM; RANGER, 1994). Ou seja, representam um "conjunto de práticas, normalmente sustentadas por regras tacitamente ou abertamente aceites e de natureza ritual ou simbólica, que procura inculcar certos valores ou normas de comportamento pela repetição, o que automaticamente implica

6 Foram elas, seguindo a mesma ordem: Sociedade Filarmónica Verdi (com o apoio do grupo de jazz "Os Galos"), Club União Ciclista do Rio de Janeiro (note-se o reenvio para o Brasil) e Club Musical União.

7 Cit. do artigo "Inabalável, a praça 11", do jornal A Noite, 14/2/1942 (AUGRAS, 1998, p. 52). Sobre a ênfase getulista no carnaval como folclore ver: AUGRAS, 1998, p. 51-52.

O Notícias Ilustrado, Lisboa, 05 jun. 1932, p. 15.

9 Diário de Lisboa, Lisboa, 13 jun. 1932, p. 6. 
continuidade com o passado", e que foram inventadas, construídas e formalmente instituídas, ainda por cima num período curto e datável (HOBSBAWM; RANGER, 1994, p. 1, tradução livre). Tal não impediu que tanto o desfile de carnaval como as marchas populares convocassem mecanismos da cultura de massas, nos seus aspectos mais ligados à divulgação massiva ${ }^{10}$ e ao espetáculo moderno: o destaque para a cenografia, o recurso a técnicos do meio teatral, a reprodução na rádio, no disco, no cinema, na televisão, etc.

Com efeito, nas décadas de 1930 e 1940 assiste-se à generalização gradual de fenómenos culturais criados ou adoptados pelas camadas mais desfavorecidas da população brasileira. O samba e o carvaval são apenas alguns desses fenómenos incorporados na cultura de massas e na cultura erudita à escala nacional. ${ }^{11}$ No caso português, destacam-se o teatro de revista, o fado e as marchas populares (MELO, 2004).

Neste contexto, a ação do Estado na arena cultural tem que ser perspectivada enquanto intervenção de um dos vários atores participantes, ao lado de intelectuais e artistas, de grupos sociais populares e das classes médias, de certos media, entre outros. ${ }^{12} \mathrm{~A}$ invenção dos desfiles das escolas de samba e das marchas populares foi assim o resultado dum complexo de interações, interesses e aspirações, onde a negociação teve papel central, assente numa circularidade (intercâmbio) cultural entre elites e povo, entre segmentos especializados e grupos populares, entre cultura erudita, popular e de massas, numa atualização da teoria de Mikhail Bakhtin ${ }^{13}$.

\section{A oficialização como passaporte: sob o signo nacionalista}

Após a oficialização, ambas as festividades se enraizaram, atingindo uma certa regularidade durante o cômputo global do século $\mathrm{XX}$, sobretudo no caso do desfile das escolas de samba. Este só faltou em 1930-31 e 1952 (69 anos com desfile em 72 anos possíveis, ou c. de $96 \%$ dos anos; total de 76 edições, dadas as repetições em 1934, 1937, 1946 e 1949-51). Nas marchas, as interrupções foram maiores (38 anos com desfile em 69 anos possíveis, ou c. de 55\% dos anos; total

\footnotetext{
${ }_{10}$ Através dos vários tipos de imprensa: de massas, especializada, de circulação nacional e/ou popular.

11 Ver capítulos de Mônica Velloso e de Rachel Soihet em FERREIRA, 2007, p. 287-350.

12 Ver: Vianna, 1995; Melo, 2001; Fernandes, 2001; Ferreira, 2007.

13 Debate sobre o tema em Fernandes, 2001, Melo, 2004 e Agostinho, 2014. Estes textos têm abordagens distintas mas que se complementam, articulando e refletindo sobre as noções de mediação, inovação, autonomia cultural e/ou controle social e ideológico.
} 
de 39 edições), mas mesmo assim todas as décadas estão pontuadas, tendo o maior hiato (de 6 anos: 1941-46) surgido numa conjuntura excepcional marcada pela II Guerra Mundial ${ }^{14}$.

Embora a oficialização tenha ocorrido sob regimes políticos distintos (democracia no Brasil, ditadura em Portugal), grande parte do período de consolidação destas festividades decorreu sob regimes ditatoriais (ou de exceção) em ambos os países, partilhando inclusivamente designações. Assim, em Portugal, à Ditadura Militar (1926-33) sucedeu o duradouro Estado Novo (1933-74); no Brasil, ao Governo Provisório de Getúlio Vargas (1930-34) sucederia pouco depois o também apodado Estado Novo (1937-45) e, mais tarde, a Ditadura Militar (1964-85).

A contrapartida para a aceitação destas festividades pelas autoridades foi a sua adequação a um certo figurino oficial, independentemente do regime político. Tal implicou uma regulamentação muito rígida da sua organização e funcionamento. Além disso, a conciliação entre um ambiente político-social assaz nacionalista até meados dos anos 1970 (em Portugal) ou 80 (no Brasil) e o carácter ultranacionalista das ditaduras dos dois países, determinou grandemente que o nacionalismo se tornasse uma característica intrínseca destas festividades numa dada fase (até a II Guerra Mundial no caso brasileiro, até 1973 no caso luso). A confluência destes fenómenos (regulamentação rígida, nacionalismo/ultranacionalismo) contribuiu decisivamente para a consagração do carácter nacional dos desfiles. A influência oficial foi assim uma constante, determinando a evolução dos eventos e a sua configuração básica (AUGRAS, 1998 e MELO, 2001, respectivamente). Neste ponto em concreto, divirjo das interpretações de Graça Índias Cordeiro e de Roberto Da Matta, por preconizarem uma desconexão do carnaval brasileiro face ao poder político. ${ }^{15}$ Estas características, comuns ao desfile de samba do Rio e às marchas populares de Lisboa, conferem-lhes grande singularidade no panorama internacional. Como sintetiza, de modo pertinente:

Tudo deixa supor que a transformação progressiva do desfile, da estrutura das escolas de samba e, particularmente, a importância cada vez maior do samba-enredo, caminham pari passu com a expectativa oficial. Não se trata de um processo linear de repressão e dominação, mas sim da construção mútua de nova modalidade de expressão popular (AUGRAS, 1998, p. 35).

\footnotetext{
${ }_{14}$ Para os desfiles de samba ver: Augras, 1998, Amaral, 2000 e Fernandes, 2001; para as marchas populares ver: Melo, 2001, p. 282-283 e espólio particular de José Ramalho (cópia dos documentos originais depositada no Gabinete de Estudos Olissiponenses da Câmara Municipal de Lisboa).

15 Ver para ambos: Cordeiro, 1997, p. 323.
} 
Quanto às marchas populares, basta mencionar que em duas ocasiões foram reativadas por motivos comemorativistas de índole nacionalista (em 1940 para celebrar a independência nacional, em 1947 para celebrar a tomada de Lisboa aos mouros de 1147), além do "Grande Desfile Popular do Mundo Lusíada" em 1973, que celebrava o Império colonial português sob o manto diáfano do luso-tropicalismo ${ }^{16}$.

Note-se ainda que, até aos anos 1970-80, o nacionalismo teve muito consenso nestes países, pois estava bastante imbuído nas próprias sociedades, daí não ter sido necessário recorrer à imposição de temas nacionalistas. O nacionalismo, na sua faceta mais fechada (ou ufanista), afrouxa devido a processos de democratização política, social e cultural subsequentes ao fim das ditaduras (em Portugal em 1974-75, no Brasil em 1985), os quais consagrarão, gradualmente, um modo mais aberto de relacionamento entre nação e mundo, influindo num perfil mais aberto de festividade, inclusive na sua formatação e regulamentação.

No caso português, apesar dos temas terem, no cômputo global de amostra representativa, menos referências nacionalistas diretas (segundo um estudo pessoal das letras das canções vencedoras entre 1932 e 1999), dado o seu enquadramento obrigatoriamente microlocal (exceto na "grande marcha", canção cantada por todos os agrupamentos de marchantes, criada em 1935 e renovada em cada edição), enquadraramse amiúde em celebrações nacionalistas, como atrás exemplifiquei, ou então continham alusões visuais nos arcos dos marchantes, como a Ponte Salazar (num tributo ao ditador ${ }^{17}$ ). Ademais, a "grande marcha" tinha um pendor mais nacionalista, e, por regra, maior visibilidade que as restantes canções. E as letras das canções de cada bairro procuravam amiúde tipos populares ou figuras históricas da tradição cultural (Santo António ou os marinheiros da epopeia, em Alfama ${ }^{18}$; a fadista Severa, para a Mouraria; o fado no bairro Alto, por causa da boémia e das casas de fado; os saloios de Benfica; o padroeiro S. Vicente no bairro homónimo), indo ao encontro da ideologia salazarista. Outra dimensão recorrente do agrado do regime remete para as inúmeras referências à cristandade, não só ao Santo António, como a S. Vicente, a Deus em abstrato, ao povo cristão (lisboeta ou português) ou à sua forte

\footnotetext{
${ }^{16}$ Sobre a instrumentalização da teoria de Gilberto Freyre pelo salazarismo ver Castelo, 1999.

${ }^{17}$ Esta ponte foi inaugurada a 06 ago 1966 e renomeada Ponte 25 de Abril após a queda do regime ditatorial.

${ }^{18}$ Bem exemplificado na letra da canção respectiva de 1955: “Ai que linha Alfama/ Da marinhagem,/ Velha equipagem/ das antigas naus,/ Página de oiro/ Da nossa História,/ Degraus de glória/ São os teus degraus/ Altares de sonhos/ De quem se preza/ Lâmpada acesa/ Pelas mãos da Fé,/ Lisboa é tua,/ E assim, doa a quem doa/ Minha Alfama, olha Lisboa/ Que linda que ela é!".
} 
crença religiosa ${ }^{19}$. Cristandade essa que significa não só um espaço de religiosidade como um referente histórico que acompanha a construção da nação portuguesa e do seu povo em armas auxiliado pelos cruzados e templários na "reconquista cristã" peninsular.

Embora o espaço físico destas celebrações seja local, a sua recepção é planetária e são vistas sobretudo como representativas da cultura desses países. Os milhões de pessoas que fora do Brasil consomem imagens ou relatos sobre o desfile de samba do Rio identificam-no imediatamente com o Brasil; aliás, esse é um dos estereótipos do Brasil, ciclicamente, anualmente, reiterado pelos meios de comunicação social, sobretudo pela televisão. Além disso, existem alguns indícios seguros: a sua influência ou imitação noutras festividades e certas características do seu espetáculo.

\section{Da nação para o mundo: replicações e internacionalização}

No caso brasileiro, as emulações serão várias, embora na bibliografia compulsada só tenha deparado com o exemplo de São Paulo. ${ }^{20}$ Ainda segundo Sebe, o "modelo carioca de escola de samba tem sido a matriz básica, reproduzida em diferentes quadrantes do país" para o "nivelamento do carnaval brasileiro" (1986, p. 75; também FERREIRA, 2004, p. 352). Talvez o contributo mais importante do desfile de samba carioca seja o fato de servir de inspiração para a organização ou funcionamento de certos aspectos doutros festejos carnavalescos: avanço como hipótese o caso de São Salvador da Bahia, que embora tenha um Carnaval centrado no "trio elétrico", foi grandemente estruturado e profissionalizado nos anos 1990, quando o do Rio já há muito estava disciplinado e 'profissionalmente' organizado, pronto a servir de modelo. Além disso, o Carnaval baiano teve desfile de escolas sambistas até $1976^{21}$.

\footnotetext{
${ }_{19}$ Leia-se o estribilho da grande marcha de 1955: "Esta Lisboa bendita,/ Feita cristã p'ra viver,/ É a menina bonita/ De quem tem olhos p'ra ver! [parágrafo] Moira sem alma nem lei,/ Quis darlhe o céu cor e luz./ E o nosso primeiro rei,/ Deu-lhe nova grei/ E o sinal da cruz!/ [par. ${ }^{\circ}$ ] Nas airosas caravelas,/ Tempo após, com génio profundo./ Cruz sangrando sobre as velas/ - Portugal dilatou o mundo! [par. ${ }^{\circ}$ E a Lisboa ribeirinha./ Ao impor sua cruz na guerra,/ Foi então a gentil rainha/ Ante a qual se curvou a Terra".

${ }^{20}$ Desfile criado em 1936, oficializado em 1967. Ver: Sebe, 1986, p. 82-83.

${ }^{21} \mathrm{Na}$ internet, está disponível um quadro ordenando escolas de samba por localidade, no Brasil e no mundo, mas nada refere quanto a possível emulação da fórmula do Rio de Janeiro ou se, fora do Rio de Janeiro, realizam desfile colectivo e competitivo (Lista de escolas de samba, 2012). Daí a minha opção por só apresentar um quadro próprio para as marchas populares de Lisboa, pois para estas existe informação suficiente e fidedigna.
} 
No caso luso, a situação ainda é mais evidente, com replicações para todos os gostos. Além das marchas se terem exibido amiúde fora do habitat natural, tendo desfilado no Estoril logo em 1932, ${ }^{22}$ nas Caldas da Rainha em 1940 (MELO, 2001), etc., também exportaram o seu modelo a todo o país (ver quadro anexo).

Assim, ao desfile noturno de 1939 para recepção ao Presidente da República em Lourenço Marques (atual Maputo), segue-se-lhe novamente a mesma cidade (em 1946), a participação no desfile de Lisboa de 1947 duma marcha da cidade vizinha de Almada e desfile na cidade nortenha de Viana do Castelo. Nota-se uma adesão crescente desde os anos 1950, alastrando por todo o país metropolitano, por algumas das suas principais cidades, incluindo das colónias. Depois da revolução de 1974, salienta-se a consolidação de marchas próprias nos concelhos contíguos à capital portuguesa. Estimo que existam marchas em praticamente todos os concelhos da Área Metropolitana de Lisboa ausentes do quadro anexo, mas não foi ainda possível reunir prova documental. Em praticamente todos os casos existiu uma colaboração entre poder político local (municipal) e associativismo voluntário local. A edição lisboeta de 1979, que recupera as marchas após o anátema revolucionário (subsequente ao golpe militar de 25/4/1974), foi centrada nas 12 marchas oriundas de freguesias dos concelhos de Mafra e Loures, dada a redução da componente propriamente lisboeta a uma "grande marcha". Também surgiram marchas populares na diáspora lusa (promotores associativos já identificados: Clube Português A Família, no Reino Unido; Kemblawarra Club, de Port Kembla, Austrália).

Em termos de influência das marchas noutras festividades populares, esta é provável no caso das rusgas de Braga, por exemplo, pois não existiam de modo tão organizado e com elementos característicos das marchas populares de Lisboa - pelo exemplo da Rusga de S. Vicente, com desfile e arco com figuras desde 1965, pelo menos (RUSGA DE SÃO VICENTE DE BRAGA, 1990, p. 11 e 27).

Ambos os eventos tiveram ainda a virtude de se terem internacionalizado em termos de performance, pois houve escolas de samba e marchas que se exibiram fora dos seus países. Assim, como exemplos lisboetas registem-se o convite da Câmara Municipal de Lisboa a jornalistas estrangeiros para acompanhamento da edição de 1990 e a atuação da marcha de Alfama nas cidades japonesas de Osaka, Ikeda e Sacai, em 1993 (MIRANDA, 1996, p. 42 e ANÓNIMO, 1993,

\footnotetext{
${ }_{22}$ Diário de Lisboa, Lisboa, 24 jun. 1932, p. 2.
} 
respectivamente). Como exemplo carioca, e para além da já aludida potente difusão televisiva planetária durante o período carnavalesco, registe-se a participação da escola de samba Beija-Flor no desfile das marchas populares de Lisboa, em $1981^{23}$.

No sentido oposto, uma das divergências mais relevantes é a importância atribuída à ruralidade e ao cruzamento entre rural e urbano no caso das marchas populares de Lisboa, sem paralelo no caso carioca.

\section{Conteúdos, estrutura e organização: onde a brasilidade e a portugalidade se tocam}

Quanto ao conteúdo do desfile de samba, importa salientar a importância dos temas de âmbito não local ou referências afins na letra do samba-enredo. Assim, a análise de conteúdo de Augras (1998, p. 107-169) para a quase totalidade dos sambas-enredo premiados entre 1948-75 demonstra a centralidade das referências ao Brasil, através do elogio do país, da nação, de seus "vultos", de sua história, da sua natureza. Exemplificando: só os conjuntos de história (categorias "tempo e memória" e "eventos e personagens"), nação (categorias "nação brasileira" e "regiões e estados do Brasil") e natureza (categoria homónima) constituem c. de 35\% do total de menções. ${ }^{24}$ Augras (1998, p. 91-92) refere que os temas ufanistas e patrióticos prevaleceram até ao início dos anos 60, tendo começado a ceder a primazia para a temática "afro-bahia" a partir de 1962 (sob a influência pioneira da escola do Salgueiro). Ainda assim, mesmo esta temática é grandemente exterior ao contexto carioca. Embora desde os anos 1970 predomine a fantasia nos sambas-enredo, as referências nacionais subsistem: segundo a análise de Augras para 1997 - que abarca os sambas-enredo das 16 escolas do "grupo especial" (isto é, dos concorrentes ao pódio) - quase $23 \%$ das menções são para o Brasil, nas vertentes assinaladas ${ }^{25}$.

Quanto ao conteúdo das marchas populares de Lisboa, importa referir desde logo a sua estreia em 1932 com trajes representando tipos populares tradicionais de vários cantos do país. Assim, a marcha vencedora da 1. ${ }^{a}$ edição apresentou-se com o trajo à moda do Minho, a

\footnotetext{
23 Já em 1973 houvera um antecedente, com a participação da "Escola de Samba Vapores do Rego", mas esta era formada por estudantes universitários brasileiros radicados em Portugal (MIRANDA, 1996, p. 41).

24 Ver: Augras, 1998, p. 292.

${ }^{25}$ Esta análise baseia-se na tese de doutoramento de Maria Laura Cavalcanti, de 1993 apud Augras, 1998, p. 294.
} 
seguinte com vestes de tricana de Leiria e de camponeses estremenhos, e a última com indumentárias regionais do Douro e Estremadura. A imagética regionalista, de fundo rural e campesino, revelava-se na alacridade dos tecidos e invulgaridade da 'convocação' de regiões tão diversas. Era, portanto, uma indumentária de traço folclórico, mas que nada tinha a ver com o folclore local, isto é, de Lisboa (MELO, 2001, p. 280). O folclore nacional será depois substituído pelo pretensamente local, mas mesmo aí as referências são também parcialmente nacionais: as peixeiras do bairro da Madragoa vêm da povoação nortenha de Ovar (daí serem designadas por varinas, corruptela de ovarinas), os saloios de Benfica, ou bairros vizinhos, provêem originariamente da região da Estremadura. Além disso, também as letras das canções das marchas revelam esses estereótipos, como explanei atrás.

As afinidades entre estes desfiles não se esgotam no conteúdo nacionalista (e ufanista) dos temas e das letras das canções. Assim, anote-se nas principais similitudes organizativas: 1) a "diferenciação moral" das escolas de samba e das marchas populares em relação a manifestações culturais populares anteriores ${ }^{26}$, como modo de se legitimarem e de se imporem; 2) o regulamento que formata o evento, estabelecendo não só as regras do concurso como instruindo sobre o tipo de organizações que podem participar e em que condições; 3) o centrar da festividade num desfile; 4) o concurso com avaliação segundo um conjunto de quesitos (em torno da canção, do tema, da música/ músicos, cenografia, coreografia, etc.); 5) a divisão de cada grupo concorrente em várias secções, incluindo uma para as coqueluches (no Rio, o "mestresala" e a "porta-bandeira"; em Lisboa, o "padrinho", a "madrinha" e, eventualmente, as "mascotes", ou seja, um par de crianças, e o "porta estandarte").

A este nível, uma das principais diferenças reside na duração do evento central: no Rio, dura duas longas noites (desde os anos 70), dispondo cada escola de samba entre 65 e 80 minutos de tempo de exibição; em Lisboa, dura uma curta noite, tendo cada marcha direito a c. de 15 minutos de desfile. Daqui decorre toda uma série de consequências relativas ao tipo de performance, ao número de participantes, ao montante do investimento, etc.

\footnotetext{
${ }^{26}$ Por exemplo, das escolas face aos cordões e grupos desordeiros apontados por Jotaefegê (ver: Gonçalves, 2003, p. 96 e 100-101) e das marchas face às deambulações de grupos informais e dançantes de sociedades recreativas e das cegadas carnavalescas (ver: Melo, 2001). O termo "diferenciação moral” é empregue por Gonçalves, 2003, p. 96.
} 


\section{Debates sobre política e cultura}

Outros pontos comuns desaguam em divergências: assim, uma mesma discussão sobre se estes eventos podiam ser considerados manifestações folclóricas teve intensidades bem variadas. Com efeito, enquanto no Brasil uma série de folcloristas questionou o carácter folclórico das escolas de samba nos anos 1960 (GONÇALVES, 2003, p. 98), em Portugal as marchas foram menos criticadas nesse âmbito durante a ditadura, dada a existência doutros pomos de discórdia mais duradouros - caso do fado, com legiões de defensores e detratores desde inícios de Novecentos ${ }^{27}$ - ou com maior alcance, como foi o caso da "autenticidade" dos "ranchos folclóricos", cuja institucionalização e homogeneização a nível nacional pela rede corporativa de "casas do povo" do Estado Novo levou certos folcloristas a lamentar a sua perda de pureza e vínculo tradicional (MELO, 2001, p. 194). Ainda assim, do interior do regime surgiram algumas críticas, com António Ferro, dirigente da propaganda e política cultural, lançando-lhes o anátema da impureza etnográfica, em $1949^{28}$, e o próprio Leitão de Barros alertando, em carta a Salazar de 1953, para a sua perda de vitalidade artística e obsolescência face ao "moderno" turismo cultural e de massas (MELO, 2001, p. 292/293). Com a queda da ditadura, a organização das marchas populares é suspensa em Lisboa por decisão das coletividades de cultura e recreio da capital, secundada por um período de forte contestação das mesmas, que só regressam em 1979. Forte animosidade essa que se estendeu ao fado, em ambos se denunciando a sua dimensão alienante e a sua colagem ou instrumentalização pelo regime ditatorial (DIONÍSIO, 1993, p. 391-392 e 330-51, respectivamente).

Este movimento tinha suas raízes na denúncia, surgida nos anos 1960, do modelo cultural oficial por parte da oposição antisalazarista, um modelo que operava a "manipulação da consciência cívica dos portugueses" e que seria designado de modo irónico por "Fado, Fátima e futebol" ou os "3 Efes". ${ }^{29}$ Como refere ainda o mesmo estudioso:

\footnotetext{
27 Ver: Nery, 2004.

28 Com efeito, Ferro organiza então um Concurso dos Ranchos Folclóricos da Beira Baixa, contraofensiva no "sentido da purificação das nossas canções e danças populares", porquanto estas estariam a ser "abastardadas pelo gosto ou desgosto das revistas, pelo vício das fitas, das pandeiretas e das marchas com as mãos na cintura" (apud Melo, 2001, p. 292).

29 Ver: Nery, 2004, p. 241.
} 
Descobrindo o potencial do Fado como veículo de afirmação propagandística, e em cuja poética - desde a implementação da censura em 1926 - ganhou expressão uma postura cívica de conformismo, de aceitação passiva da realidade social e política como dados de um destino inelutável, o Salazarismo rapidamente transformaria o Fado na 'canção nacional'. [...] Esclareça-se que este contexto político-ideológico geral não implica necessariamente qualquer política de arregimentação directa do Fado ou dos fadistas por parte do regime, mas antes uma colagem estratégica das autoridades salazaristas a um género cuja popularidade atingiu manifestamente o auge e cujos conteúdos poéticos tradicionais, após um quarto de século de condicionamento censório, se revelam de uma utilidade política da maior conveniência... Tal como se procurará colar, no plano internacional, à imagem de prestígio crescente de Amália Rodrigues. (NERY, 2004, p. 238-239)

\section{Em jeito de conclusão}

Os desfiles das escolas de samba do Rio de Janeiro e das marchas populares de Lisboa, âmago do presente estudo, constituíram-se no século XX como festividades centrais nos respectivos países. Originalmente manifestações populares urbanas locais, cedo se tornaram reflexo da projeção duma cultura 'nacionalizada' no/pelo país e no/pelo exterior. Foram o resultado de complexos processos históricos de invenção de tradições, interagindo com processos mais vastos de folclorização, e de complexas negociações entre seus atores principais e as autoridades públicas para a sua viabilidade, reconhecimento e centralidade. Ademais, a recuperação ou suposta criação de cultura popular de inspiração tradicional (seja pela ligação à quadra carnavalesca ou juniana, seja pela ligação a festividades anteriores) foi realizada convocando também mecanismos da cultura de massas, nos seus aspectos mais ligados à divulgação e ao espetáculo moderno, cada vez mais presentes à medida que se avança no século XX.

Este processo negocial conduziu não só a uma disciplinação dos eventos e à sua padronização rígida como também ao reforço das componentes nacional e nacionalista. Tal desenlace está fortemente relacionado com a existência de ditaduras durante grande parte do período de génese e consolidação dos eventos, com seus interesses de edificação duma política cultural assente num nacionalismo cultural e com o ambiente social fortemente nacionalista vigente em ambos os países, ambiente este que se dilui no quarto quartel do século $\mathrm{XX}$, 
primeiro em Portugal, com a revolução de 1974, e no Brasil, com o fim da Ditadura Militar, em 1985.

Os desfiles que comparámos neste estudo ficaram assim intrincados na construção duma identidade nacional integradora (porventura mais saliente no caso brasileiro, e apesar do formato de competição) e conciliadora - por isso se podem considerar enquanto desfiles da nação. Contudo, vozes críticas houve que debateram a sua autenticidade etnográfica, cuja intensidade foi mais evidente, ou mais precoce, no caso brasileiro. Já no caso português, o período imediatamente pósditatorial (de 1974 em diante) não só pôs em causa o carácter popular e sadio das marchas populares (e do fado) como levou ao cancelamento da sua organização durante vários anos, chamando mais uma vez a atenção para a porosidade das ligações entre festa, sociedade civil e Estado (ditatorial). Tal porosidade afigura-se ter particular incidência em festividades susceptíveis de incorporar aspectos básicos dum ideário ultranacionalista como os preconizados pelas ditaduras, daí a especial atenção dos poderes públicos para com os casos estudados no presente artigo. Nesta análise procurou-se inventariar e analisar as principais homologias de processo histórico, de conteúdo, de estrutura e organização entre estes dois desfiles populares urbanos. Tais similitudes foram suficientemente fortes para justificar uma abordagem comparativa.

Ao propor-se uma análise mais detalhada do papel do Estado na construção duma festa nacional não se pretendeu desvalorizar a relevância do papel doutros atores sociais centrais, como as elites letradas e os grupos sociais desfavorecidos ligados ao evento (ao carnaval, ao samba e/ou ao desfile de samba, no caso do Brasil; às marchas populares, ao fado e ao teatro de revista, no caso de Portugal), até porque são estes atores (e ainda segmentos das classes médias) que elaborarão o cerne duma partilha cultural nacional de pendor integrador, a partir da ideia duma identidade nacional baseada (ou fautora) numa certa tradição (ainda que inventada), na coesão social e na mestiçagem (no caso brasileiro), e da incorporação nessa ideia do contributo de segmentos segregados e/ou desfavorecidos, como o das comunidades negras e das favelas, novamente para o caso brasileiro, e de grupos/ elementos rurais, no caso português. O que se buscou foi aprofundar o conhecimento da negociação entre Estado, sociedade civil organizada, media e outros atores sociais e verificar o impacto das distintas conjunturas políticas e culturais na evolução das dinâmicas da circularidade e da identidade culturais. Com efeito, no período temporal abarcado, o Estado (central e local), juntamente com grupos das elites (das artes, letras e media), 
torna-se também ele regulador e mediador político-cultural nesse processo de incorporação e negociação do contributo de grupos sociais populares na reelaboração da identidade cultural nacional, em especial no quadro de festas populares que ganharam âmbito nacional e projeção internacional.

Quadro da replicação das marchas populares de Lisboa (século XX)

\begin{tabular}{|c|c|c|}
\hline Data & Local & Caracterização \\
\hline $\begin{array}{l}1939,1946 \\
1958 \mathrm{e} \\
1966-67\end{array}$ & $\begin{array}{l}\text { Lourenço } \\
\text { Marques } \\
\text { (actual Maputo, } \\
\text { Moçambique) }\end{array}$ & $\begin{array}{l}\text { desfile de } 12 / 8 / 1939 \text { para recepção ao presidente da República, } \\
\text { organizado por casas regionalistas e associações Indo- } \\
\text { Portuguesa e dos Naturais da Colónia, com c. } 20 \text { mil assistentes; } \\
\text { mais afim ao figurino lisboeta foi a edição de } 1946 \text {, com } \\
\text { concurso de canções para marchas votado pelo público emitido } \\
\text { pelo Rádio Clube de Moçambique e desfile no estádio do Clube } \\
\text { Ferroviário, na quadra carnavalesca, verão local (também } \\
\text { colaboraram o diário Notícias e várias associações) }\end{array}$ \\
\hline 1947 & Almada & 1 marcha para participar no desfile de Lisboa \\
\hline 1949 & $\begin{array}{l}\text { Viana do } \\
\text { Castelo }\end{array}$ & desfile de marchas (1 marcha continuará a exibir-se nos anos 50) \\
\hline 1950 & Oeiras & $\begin{array}{l}1 \text { marcha celebra a elevação a vila (1759); regressa nos anos } \\
1980\end{array}$ \\
\hline $1952-55$ & Évora & 1 associação desportiva assegura continuidade entre 1953-55 \\
\hline 1953 & Estremoz & concurso com 5 marchas \\
\hline $1954-$ & Alcácer do Sal & concurso de marchas, com 30 anos em 1984 \\
\hline 1954 & Covilhã & $\begin{array}{l}\text { concurso de marchas, org. pela Fundação Nacional para a Alegria } \\
\text { no Trabalho, depois 'reconvertido' para "ranchos folclóricos" } \\
\text { (exclusivo para os seus "centros de recreio popular" locais) }\end{array}$ \\
\hline 1956 & Montijo & $\begin{array}{l}\text { Festas de S. Pedro integram } 1 \text { marcha do Bairro dos Pescadores } \\
\text { local }\end{array}$ \\
\hline $\begin{array}{c}1956-57 \\
1966 \mathrm{e} \\
1968\end{array}$ & Porto & $\begin{array}{l}\text { "concurso de rusgas populares" (org. do Diário do Norte), } \\
\text { depois "marchas sanjoaninas", para freguesias portuenses } \\
\text { (org. inicial dos Postos Emissores Reunidos e Jornal de } \\
\text { Noticias) em 1957, } 1966 \text { e 1968, pelo menos }\end{array}$ \\
\hline 1957 & $\begin{array}{l}\text { Moçâmedes } \\
\text { (Angola) }\end{array}$ & $\begin{array}{l}\text { desfile no Estádio Comandante Fragoso de Matos a } 16 \text { e 26/IX, } \\
\text { seguidas de verbena (org. pelos jornais Sul e } O \text { Namibe e com a } \\
\text { participação de clubes desportivos locais) }\end{array}$ \\
\hline 1962 e 1969 & $\begin{array}{l}\text { Nova Lisboa } \\
\text { (actual Huambo, } \\
\text { Angola) }\end{array}$ & $\begin{array}{l}\text { desfile de } 1962 \text { no campo do Sporting local, integrado nas } \\
\text { comemorações do } 50 .^{\circ} \text { aniversário da cidade, com c. } 8 \text { mil } \\
\text { espectadores e uma marcha extra vinda do Bailundo }\end{array}$ \\
\hline $1963-71$ & $\begin{array}{l}\text { Lobito } \\
\text { (Angola) }\end{array}$ & $\begin{array}{l}\text { mentor principal foi o compositor e coreógrafo António Branco } \\
\text { Pedreira, maestro e acordeonista do Rancho Folclórico da Casa } \\
\text { do Ribatejo local, apesar de ser minhoto de naturalidade }\end{array}$ \\
\hline 1964 e 1971 & $\begin{array}{l}\text { Sá da Bandeira } \\
\text { (Angola) }\end{array}$ & $\begin{array}{l}\text { desfile com trajes folclóricos campesinos da metrópole, arcos } \\
\text { com figuras minhotas, motivos florais, mapa de Angola, etc.; em } \\
1971 \text { também houve uma marcha especial, ou "Grande Marcha" }\end{array}$ \\
\hline 1966 & Gaia & 1 marcha para participar no Porto \\
\hline 1966 & Fundão & concurso de marchas, até 1990 \\
\hline
\end{tabular}


Quadro da replicação das marchas populares de Lisboa (século XX) (conclusão)

\begin{tabular}{|c|l|l|}
\hline Data & \multicolumn{1}{|c|}{ Local } & \multicolumn{1}{c|}{ Caracterização } \\
\hline $197 ?$ & Setúbal & concurso de marchas, retomadas em 1985 \\
\hline 1970 & Amarante & $\begin{array}{l}\text { concurso de marchas nas Festas de S. Gonçalo, até 1972 e } \\
\text { retomadas em 1980 }\end{array}$ \\
\hline 1979 & Mafra & $\begin{array}{l}\text { participação na "Grande Marcha de Lisboa"; desfile de } \\
25 \text { freguesias em 1982, sob a égide de Beatriz Costa, antiga } \\
\text { jurada e madrinha nas marchas lisboetas }\end{array}$ \\
\hline 1979 & Loures & $\begin{array}{l}\text { Participação na "Grande Marcha de Lisboa"; concurso de } \\
\text { marchas desde 1994, pelo menos }\end{array}$ \\
\hline $198 ?$ & Cascais & concurso de marchas \\
\hline $198 ?$ & Oeiras & desfile de marchas \\
\hline $198 ?$ & Almada & desfile de marchas \\
\hline 1985 & Sesimbra & desfile de marchas, pelo menos desde então \\
\hline 1994 & Pombal & $\begin{array}{l}\text { edições contínuas desde 1994, organizadas pela associação } \\
\text { Os Amigos de Santo António e o município local }\end{array}$ \\
\hline 1999 & Barreiro & desfile de marchas, pelo menos neste ano \\
\hline
\end{tabular}

Fontes: Melo, 2001, p. 293/294; Melo, 2007, p. 10-13 (para as ex-colónias); relatórios de 1957, 1958 e 1967 da Federação das Colectividades do Distrito do Porto de Educação, Recreio e Desporto (para Porto e Gaia); Comissão Organizadora, 1990 (para Fundão); Anónimo, 1983 (para Mafra); Anónimo, 1993 (para Loures, Oeiras e Almada nos anos 1970/80); Garcia, 1981/82 (para Cascais); Anónimo, 1986a, Anónimo, 1986b e Anónimo, 1988 (para Sesimbra); Anónimo, 2011 (para Pombal); Anónimo, 1999 (para Barreiro).

\section{Referências}

AGOSTINHO, Zilmar Luiz dos Reis. O debate entre a cultura popular e a cultura erudita no carnaval carioca. Textos escolhidos de cultura e arte populares, Rio de Janeiro, v. 11, n. 2, p. 67-89, nov. 2014.

AMARAL, Pedro. Trinta anos de samba-enredo. Rio de Janeiro: ZFM, 2000.

AUGRAS, Monique. O Brasil do samba-enredo. Rio de Janeiro: Editora Fundação Getúlio Vargas, 1998.

BEIRED, José Luis Bendicho; CAPELATO, Maria Helena; PRADO, Maria Lígia Coelho (Org.). Intercâmbios políticos e mediações culturais nas Américas. Assis; São Paulo: FCL-Assis-UNESP Publicações e Laboratório de Estudos de História das Américas da USP, 2010.

BETHELL, Leslie (Dir.). A América Latina após 1930. V. VI-VIII, São Paulo: Edusp, 2005. BLOCH, Marc. Pour une histoire comparée des sociétés européennes. In: BECKER, Annette; BLOCH, Étienne (Comp.). Marc Bloch: l'histoire, la guerre, la résistance. Paris: Gallimard, 2006. p. 347-380.

CARNEIRO, Maria Luiza Tucci. Livros proibidos, idéias malditas. 2. ed. São Paulo: Ateliê Editorial, 2001.

CASTELO, Cláudia. "O modo português de estar no mundo”: o luso-tropicalismo e a ideologia colonial portuguesa. Porto: Edições Afrontamento, 1999.

CASTELO-BRANCO, Salwa El-Shawan, BRANCO, Jorge Freitas (Orgs.). Vozes do povo: a folclorização em Portugal. Oeiras: Celta Editora, 2003.

CAVAZZA, Stefano. Piccole patrie. Bolonha: Il Mulino, 1997.

CORDEIRO, Graça Índias. Um lugar na cidade: quotidiano, memória e representação no bairro da Bica. Lisboa: Publicações Dom Quixote, 1997. 
COSTA, Cristina. Teatro e censura: Vargas e Salazar. São Paulo: Edusp, 2010. DIONÍSIO, Eduarda. Títulos, acções, obrigações (a cultura em Portugal, 1974-1994). Lisboa: Edições Salamandra, 1993.

FERREIRA, Felipe. O livro de ouro do Carnaval brasileiro. Rio de Janeiro: Ediouro, 2004. FERREIRA, Jorge; DELGADO, Lucilia de Almeida Neves (Org.). O Brasil republicano. 2. ed. Rio de Janeiro: Civilização Brasileira, 2007. v. 2.

FERNANDES, Nelson da Nóbrega. Escolas de samba: sujeitos celebrantes e objectos celebrados. Rio de Janeiro: Prefeitura da Cidade do Rio de Janeiro, 2001.

FIUZA, Alexandre Felipe. "Censura en España, Brasil y Portugal: esa cámara de torturar palabras y sonidos durante las dictaduras en las décadas de 1960 y 1970", Espéculo: Revista de estudios literarios, Madrid, 2005. Disponível em: $<$ http://www.ucm.es/info/ especulo/numero30/censura.html>. Acesso em: 20 abr. 2015.

. Entre um samba e um fado: a censura e a repressão aos músicos no Brasil e em Portugal nas décadas de 1960 e 1970. Tese (Doutorado) - Faculdade de Letras, Universidade Estadual Paulista, Assis: UNESP, 2014.

GONÇALVES, Renata de Sá. Cronistas, folcloristas e os ranchos carnavalescos: perspectivas sobre a cultura popular. Estudos Históricos, Rio de Janeiro, n. 32, p. 89-105, 2003.

GUIMARÃES, Lucia Maria Paschoal et al. (Org.). Afinidades atlânticas: impasses, quimeras e confluências nas relações luso-brasileiras. Rio de Janeiro: Quartet, 2009.

HAUSER, Claude et al. (Dir.). La diplomatie par le livre. Paris: Nouveau Monde, 2011. HOBSBAWM, Eric; RANGER, Terence (Ed.). The invention of tradition. 2. ed. Cambridge: Cambridge University Press, 1994.

LOPES, Cláudia Neves. Les relations éditoriales entre le Brésil et le Portugal. Paris: Universidade Paris VII, 1998 (tese doutorado).

MANN, Michael. Fascists. Cambridge: Cambridge University Press, 2004.

MELO, Daniel. Nelson da Nóbrega Fernandes, Escolas de samba: sujeitos celebrantes e objetos celebrados, Rio de Janeiro, 1928-1949, Análise Social, Lisboa, v. XXXIX, n. 170, p. 194-200, 2004. Disponível em: <http://analisesocial.ics.ul.pt/documentos/12 18705284L7iPH4er1Tt49YW1.pdf>. Acesso em: 14 maio 2015.

MELO, Daniel. Out of sight, close to the heart: regionalist voluntary associations in the Portuguese empire. e-Journal of Portuguese History, Providence e Porto, v. 5, n. 1, p. 1-18, 2007. Disponível em: <https://www.brown.edu/Departments/Portuguese Brazilian_Studies/ejph/html/issue9/html/dmelo_main.html>. Acesso em: 20 abr. 2015. $\overline{\text { Sociais, }} 2001$.

. Salazarismo e cultura popular (1933-1958). Lisboa: Imprensa de Ciências MILZA, Pierre. Les fascismes. N. ed. Paris: Seuil, 1991.

MIRANDA, António. Ai! Vai Lisboa!... com as marchas populares. In: ALVES, Maria da Trindade Mexia et al. O santo do menino Jesus: Santo António. Lisboa: Instituto Português de Museus, 1996. p. 35-44.

NERY, Rui Vieira. Para uma história do fado. Lisboa: Público, 2004.

PALACIOS, Marco (Dir.). Historia general de América Latina. Paris: UNESCO/ Editorial Trotta, 2008. v. VIII.

PASETTI, Mateo (Dir.). Progetti corporativi tra le due guerre mondiali. Roma: Carocci editore, 2006.

PAULO, Heloísa. Estado Novo e propaganda em Portugal e no Brasil. Coimbra: Livraria Minerva, 1994.

PAXTON, Robert O. The anatomy of fascism. New York: Penguin, 2005. 
PINTO, António Costa (Ed.). Rethinking the nature of fascism. Londres e New York: Palgrave Macmillan, 2010.

RUSGA DE SÃO VICENTE DE BRAGA. 25 anos 1965-1990 Rusga de S. Vicente Braga. Braga: Rusga de São Vicente de Braga - Grupo Etnográfico do Baixo Minho, 1990.

SARMENTO, Cristina Montalvão; GUIMARÃES, Lúcia Maria Paschoal (Coord.). Culturas cruzadas em português: redes de poder e relações culturais (Portugal-Brasil, séc. XIX-XX). Coimbra: Almedina, 2010.

SEBE, José Carlos. Carnaval, carnavais. São Paulo: Ática, 1986.

SOBRAL, José Manuel. A formação das nações e o nacionalismo: os paradigmas explicativos e o caso português. Análise Social, Lisboa, v. XXXVII, n. 165, p. 1093-1126, 2003. TINHORÃO, José Ramos. Fado: dança do Brasil, cantar de Lisboa. Lisboa: Editorial Caminho, 1994.

TORGAL, Luís Reis, PAULO, Heloísa (Coord.). Estados autoritários e totalitários e suas representações. Coimbra: Imprensa da Universidade, 2008.

VIANNA, Hermano. O mistério do samba. Rio de Janeiro: Jorge Zahar Editor e Editora UFRJ, 1995.

\section{Fontes}

ANÓNIMO. Barreiro. Elo associativo, Lisboa, n. 7, jan.-mar. 1999, p. 5.

ANÓNIMO. Beatriz Costa relembra desfiles. A Capital, Lisboa, 24 maio 1983, p. 13.

ANÓNIMO. Marchas de Santo António desfilam por Pombal. Tinta Fresca, Pombal, n. 128,8 jun. 2011, s.p.

ANÓNIMO. Marchas populares. Boletim Informativo da Federação Portuguesa das Colectividades de Cultura e Recreio, Lisboa, n. 41, dez. 1993.

ANÓNIMO. Sesimbra. Movimento Cultural, Setúbal, n. 2, jan. 1986a, p. 124.

ANÓNIMO. Sesimbra. Movimento Cultural, Setúbal, n. 3, dez. 1986b, p. 157.

ANÓNIMO. Sesimbra. Movimento Cultural, Setúbal, n. 5, dez. 1988, p. 116.

COMISSÃO ORGANIZADORA. Marchas dos santos populares do Fundão. Fundão: Gráfica União da Beira, 1990.

Diário de Lisboa, Lisboa, 13 jun. 1932, p. 6.

Diário de Lisboa, Lisboa, 24 jun. 1932, p. 2.

Lista de escolas de samba. In: Wikipédia, a enciclopédia livre. 2012. Disponível em: $<$ http://pt.wikipedia.org/wiki/Anexo:Lista_de_escolas_de_samba\#BRASIL $>$. Acesso em: 20 abr. 2015.

GARCIA, Bela. Trajos típicos saloios de 1900. Arquivo de Cascais, Cascais, Câmara Municipal, n. 4, p. 121-122, 1981/82.

FEDERAÇÃO DAS COLECTIVIDADES DO DISTRITO DO PORTO DE EDUCAÇÃO, RECREIO E DESPORTO. Relatório e contas, Porto, 1958.

FEDERAÇÃO DAS COLECTIVIDADES DO DISTRITO DO PORTO DE EDUCAÇÃO, RECREIO E DESPORTO. Relatório e contas, Porto, 1959.

FEDERAÇÃO DAS COLECTIVIDADES DO DISTRITO DO PORTO DE EDUCAÇÃO, RECREIO E DESPORTO. Relatório e contas, Porto, 1968.

O Notícias Ilustrado, Lisboa, 05 jun. 1932, p. 15. 